Article

\title{
The Effects of Oxygen Functional Groups on Graphene Oxide on the Efficient Adsorption of Radioactive Iodine
}

\author{
Qian Zhang ${ }^{1} \oplus$, Yangyang Gao ${ }^{1}$, Zhanglian $\mathrm{Xu}^{1, *}$, Sheng Wang ${ }^{1, *}$, Hisayoshi Kobayashi ${ }^{2}$ \\ and Jie Wang ${ }^{1, *}$ \\ 1 Shaanxi Key Laboratory of Advanced Nuclear Energy and Technology, and Shaanxi Engineering Research \\ Center of Advanced Nuclear Energy, School of Nuclear Science and Technology, Xi'an Jiaotong University, \\ Xi'an 710049, China; imzhangqian@stu.xjtu.edu.cn (Q.Z.); gyy2019@stu.xjtu.edu.cn (Y.G.) \\ 2 Department of Chemistry and Materials Technology, Kyoto Institute of Technology, Matsugasaju, Sakyo-ku, \\ Kyoto 606-8585, Japan; hisabbit@yahoo.co.jp \\ * Correspondence: xuzhanglian@xjtu.edu.cn (Z.X.); shengwang@xjtu.edu.cn (S.W.); \\ wangjie1@xjtu.edu.cn (J.W.); Tel.: +86-177-7897-3029 (Z.X.); +86-137-5707-3588 (S.W.); \\ +86-189-9161-2872 (J.W.)
}

Received: 22 November 2020; Accepted: 14 December 2020; Published: 17 December 2020

check for updates

\begin{abstract}
Oxygen-containing functional groups tend to induce a strong interaction between solid adsorbents and iodine molecules, yet have not been systematically investigated. Herein, on the basis of a series of nitric acid-treated graphene oxide (GO) with different contents of oxygen functional groups for iodine adsorption, it was found that the iodine uptake capacity is proportionate to the oxygen content and the diversities of oxygen-containing groups. The density functional theory (DFT) calculation results also suggest that oxygen-containing groups result in strong interactions between iodine molecules and the adsorbents through a covalent bond-forming process, among which -OH groups possess a higher adsorption energy averagely. Such theoretical and experimental work deepens our understanding of the effects of oxygen functional groups on iodine adsorption and provides novel ideas for future design and synthesis of high-performance solid adsorbents for radioactive iodine.
\end{abstract}

Keywords: iodine adsorption; DFT method; oxygen-containing functional group; graphene oxide

\section{Introduction}

Nuclear power has made great contributions to the society due to the high-power density and low greenhouse-gas emission [1,2]. However, the nuclear industry is always accompanied by the production of nuclear waste (e.g., spent nuclear fuel) or hazardous environmental release [3,4]. Several radioactive gases $\left({ }^{129} \mathrm{I},{ }^{131} \mathrm{I},{ }^{85} \mathrm{Kr}\right.$, and $\left.{ }^{127} \mathrm{Xe}\right)$ are formed during the fission process [5]. Among them, ${ }^{129} \mathrm{I}$ and ${ }^{131} \mathrm{I}$ (half-lives being $\sim 1.57 \times 10^{7}$ years and 8.02 days, respectively) will be involved in the metabolic process of human and eventually cause thyroid injury $[6,7]$. Therefore, these two iodine radioisotopes must be captured efficiently and stored securely. Up to date, loads of adsorbents including silica [8], chalcogen-based aerogels [9], activated carbon [10], zeolites [11,12] and porous frameworks [13-16] have been studied during the last few decades.

In order to improve the surface chemistry of solid adsorbents for higher iodine uptake, heteroatom doping (e.g., nitrogen doping) has drawn great attention since their adsorption capacity can be effectively strengthened through efficient surface modification [17-20]. Recently, Kangxin Xiao et al. has successfully synthesized N-doped porous carbons from orange peel waste, the iodine adsorption capacity of which was up to $2252 \mathrm{mg} \cdot \mathrm{g}^{-1}$ [10]. Meanwhile, we noticed that oxygen doping might 
have similar effects as well. For example, Deng et al. studied the surface features and adsorption behaviors of adsorbents from sludge to methylene blue and iodine, and the X-ray photoelectron spectroscopy (XPS) suggested that the functional groups with high contents of oxygen on the surface of adsorbent served as active sites for the adsorption process [21]. S. S. Zyryanov et al. attributed the most intense line at $529.6 \mathrm{eV}$ in the XPS spectra to a chemical bond between oxygen and iodine during the investigation of a stainless-steel surface irradiated with protons in an iodine medium. They believe that one of the forms of iodine is also due to the O-I bond [22]. During the systematic investigation of the adsorption characteristics of radioiodine molecules on three kinds of low-index surfaces of $\mathrm{Cu}_{2} \mathrm{O}$, the calculation was carried out using first principles density functional with periodic slab models. For the $\mathrm{Cu}_{2} \mathrm{O}(100)$ surface, it is unusually found that $\mathrm{I}_{2}$ molecule moves to the nearby $\mathrm{O}_{s}$ position (denoted as $\mathrm{O}_{\mathrm{s} 1}$ ) after being optimized in the case of $\mathrm{Cu}_{\mathrm{s}}$ site, indicating that the adsorption of $\mathrm{I}_{2}$ molecule by surface oxygen atom is prior to that of copper ones [23]. Debasis Banerjee et al. reported two microporous metal organic frameworks for $\mathrm{I}_{2}$ adsorption. Both the single-crystal X-ray diffraction and Raman spectroscopy reveal distinct sorption sites of molecular $\mathrm{I}_{2}$ to the phenyl- and phenol-based linkers stabilized by the I $\cdots \pi$ and $\mathrm{I} \cdots \mathrm{O}$ interactions, which favors the selective uptake of iodine over water vapor [24].

With the characteristics of easy preparation, good chemical and thermal stabilities, porous carbon possessing large surface area and high porosity has drawn a great deal of attention as an ideal adsorbent for iodine capture. Moreover, carbon materials have shown the possibility of overcoming the weak interaction with the iodine gases through surface functionalization. Thus, a series of oxygen-rich microporous activated carbons were synthesized in our previous work [25]. A positive correlation was found between the iodine uptake value and the oxygen content in the iodine adsorption experiments. The sample with the highest oxygen content displayed an iodine capture capacity up to $6.44 \mathrm{~g} \cdot \mathrm{g}^{-1}$, preliminarily suggesting the effects of oxygen. However, apart from oxygen-containing functional groups $(-\mathrm{OH},-\mathrm{COC}, \mathrm{C}=\mathrm{O}$ and $-\mathrm{COOH})$, there are several influencing factors including the specific surface areas (SSAs), pore size and pore volume, related to the iodine adsorption performance of porous carbon materials. More complicatedly, the textural properties such as SSA and pore volume vary according to the different oxygen content on the carbon materials $[25,26]$. Variability in both oxygen content and pore size is not ideal for studies aimed at determining the effect of the former. As a result, experiments and calculations in this field have not been done or reported before. Therefore, in this study we developed a series of nitric acid-treated samples based on graphene oxide, which were used to investigate the impact of oxygen content since the previously mentioned factors have negligible effects on them. To further reveal the interactions between oxygen-containing functional groups and iodine molecules, density functional theory (DFT) calculations were also performed, which prove the experimental results theoretically. Both the experiment and calculation results offer a new insight for the future design of solid adsorbents for iodine adsorption.

\section{Materials and Methods}

\subsection{Material Synthesis}

Graphene oxide (GO) was prepared by chemical exfoliation of graphite according to an improved Hummers method, which was then dispersed by sonochemical irradiation. Then, $1 \mathrm{~g}$ of 2000 mesh natural graphite, $34 \mathrm{~mL}$ of $\mathrm{H}_{2} \mathrm{SO}_{4}$ and $0.74 \mathrm{~g} \mathrm{NaNO}_{3}$ were mixed together, which was then stirred constantly in an ice bath. Next, $5 \mathrm{~g} \mathrm{KMnO}_{4}$ was added gradually while stirring. The temperature of the mixture was kept below $20^{\circ} \mathrm{C}$ throughout the whole process by cooling. Subsequently, the mixture was stirred at $35^{\circ} \mathrm{C}$ for $3 \mathrm{~h}$ and diluted with deionized water $(250 \mathrm{~mL})$. The color of the mixture changed into bright yellow after $4 \mathrm{~mL}$ of $30 \% \mathrm{H}_{2} \mathrm{O}_{2}$ was added. The mixture was then ultrasonically treated for $1 \mathrm{~h}$. The possible residual metal ions were removed by filtering and washing with $1 \mathrm{~L}$ of 1:10 $\mathrm{HCl}$ aqueous solution, which was then removed by $1 \mathrm{~L}$ of deionized water. The GO suspension was freeze-dried before being used. 
The frozen $\mathrm{GO}(400 \mathrm{mg})$ were dissolved in $40 \mathrm{~mL}$ of nitric acid $\left(\mathrm{HNO}_{3} 68 \%\right)$, and a homogeneous mixture was obtained after $30 \mathrm{~min}$ sonication. After stirring for $1 \mathrm{~h}$ intensely, the mixture was transferred into a $50 \mathrm{~mL}$ Teflon-lined autoclave, sealed and heated at $100^{\circ} \mathrm{C}, 110^{\circ} \mathrm{C}$ and $120^{\circ} \mathrm{C}$ for $6 \mathrm{~h}$ and the samples were labeled as GO-100, GO-110 and GO-120, respectively. The suspend solution was cooled to room temperature naturally. The final product was collected by centrifuging the mixture, and then dried in vacuum for further use after being washed with deionized water for multiple times.

\subsection{Characterization}

A CHN elemental analysis was performed using a vario EL cube elemental analyzer (Elementar, Langenselbold, Germany). The surface structure of the sample and energy dispersive spectroscopy (EDS) was obtained by a GeminiSEM 500 instrument (Carl Zeiss, Oberkochen, Germany). Transmission electron microscopy (TEM) was performed on a JEOL JEM-F200 (HR) instrument (JEOL LTD, Tokyo, Japan). The chemical state of the samples was analyzed by X-ray photoelectron spectroscopy using an AXIS ULtrabld instrument (Kratos, Manchester, UK). High-resolution spectra were charge corrected to the $\mathrm{C} 1 \mathrm{~s}$ peak at $284.6 \mathrm{eV}$.

\subsection{Iodine Adsorption Measurements}

Approximately $20 \mathrm{mg}$ of GO/GO-100/GO-110/GO-120 and excess amounts of iodine crystals were placed in two $5 \mathrm{~mL}$ beakers, respectively. The beakers were then transferred into a sealed glass vessel. The adsorption experiment was carried out at $75^{\circ} \mathrm{C}$ under normal pressure. The adsorption amount was monitored by recording the sample mass as a function of time. The uptake capacity $Q_{t}$ was calculated using Equation (1), in which $\mathrm{m}_{0}$ is the initial mass of GO/GO-100/GO-110/GO120, and $\mathrm{m}_{\mathrm{t}}$ is the mass after $t$ minutes of adsorption.

$$
\mathrm{Qt}=\left(\mathrm{m}_{\mathrm{t}}-\mathrm{m}_{0}\right) / \mathrm{m}_{0}
$$

\subsection{Calculation Method}

DFT calculations were carried out using Gaussian09 program (Gaussian, Wallingford, CT, USA). The B3LYP functional is one of the most popular and accurate functionals. The 6-311G $(\mathrm{d}, \mathrm{p})$ basis sets were used for $\mathrm{H}, \mathrm{C}$ and $\mathrm{O}$ atoms. For I atoms, the LANL2DZ, i.e., Los Alamos effective core potential together with double valence set (D95V) was employed.

\section{Results and Discussion}

\subsection{The Morphology of GO after $\mathrm{HNO}_{3}$ Treatment}

The morphology of the samples was first studied via SEM. As demonstrated in Figure 1a,d, the surface of the original graphene oxide is relatively smooth. After $\mathrm{HNO}_{3}$ treatment by a simple hydrothermal reaction, the surfaces of all the samples obtained at different temperatures $\left(100{ }^{\circ} \mathrm{C}\right.$, $110{ }^{\circ} \mathrm{C}$ and $120^{\circ} \mathrm{C}$ ) become rough (Figure $1 \mathrm{~b}-\mathrm{d}, \mathrm{f}-\mathrm{h}$ ). A large number of wrinkles and cracks are distributed unevenly on the observed surfaces, which may be due to the strong oxidation effect of $\mathrm{HNO}_{3}$. With the temperature further increasing to higher levels, the cracks and wrinkles on the surface (e.g., GO-120) became more evident. In addition, transmission electron microscopy (TEM images in Figure $2 \mathrm{~b}-\mathrm{d}$ ) reveals that the $\mathrm{HNO}_{3}$-treated graphene oxide remains the same as untreated graphene oxide nanosheets (Figure 2a) in the microscopic morphology despite the change in macroscopic morphology after $\mathrm{HNO}_{3}$ treatment. 

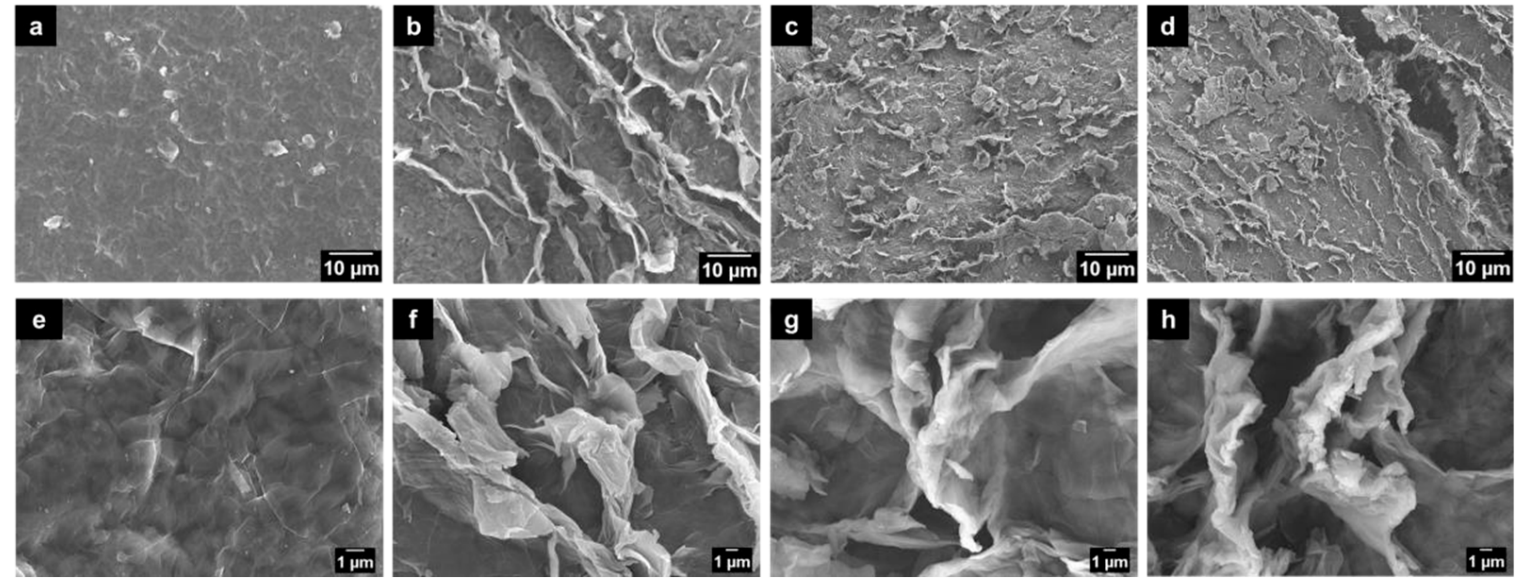

Figure 1. SEM images of (a,e) graphene oxide (GO), (b,f) GO-100, (c,g) GO-110 and (d,h) GO-120 with different magnification.
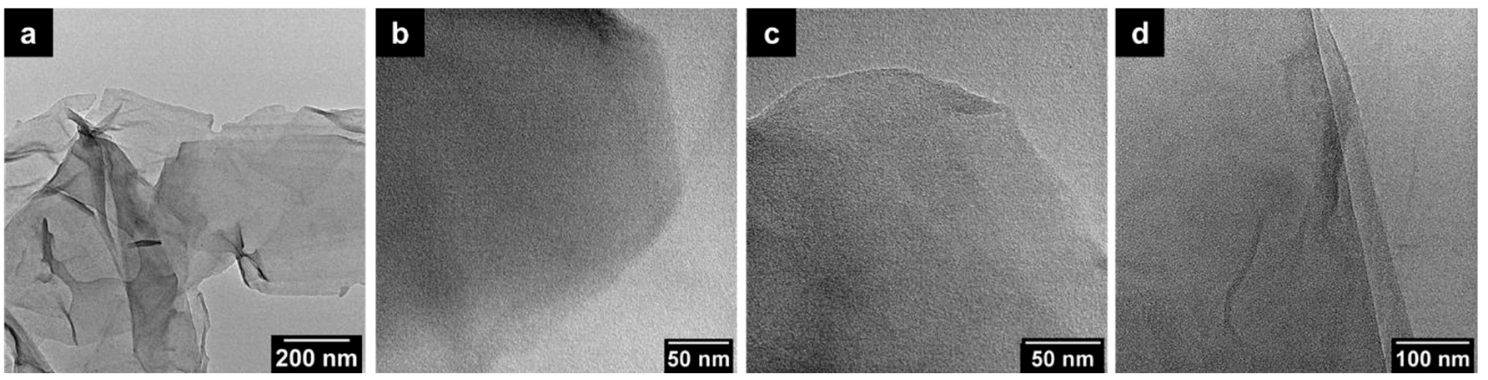

Figure 2. TEM images of (a) GO, (b) GO-100, (c) GO-110 and (d) GO-120.

\subsection{Oxygen Functional Groups}

The elemental compositions of the samples were further measured by $\mathrm{CHN}$ analysis. Table 1 shows the elemental content of all the samples. According to the results, the oxygen content of GO was the lowest (48.86 wt.\%) and showed a slight upward trend after $\mathrm{HNO}_{3}$ treatment. More specifically, the oxygen content increased from $50.60 \mathrm{wt} . \%$ to $52.04 \mathrm{wt} . \%$ as the temperature increased from $100{ }^{\circ} \mathrm{C}$ to $120{ }^{\circ} \mathrm{C}$. Similarly, the atomic ratio of $\mathrm{C} / \mathrm{O}$ decreased from 1.51 to 1.23 , indicating the existence of rich oxygen content in the $\mathrm{HNO}_{3}$-treated GOs. To further verify the intrinsic properties of the oxygen, the X-ray photoelectron spectroscopy was performed. The spectra were charge corrected (C $1 \mathrm{~s}$ at $284.6 \mathrm{eV}$ ) and peak fitting of the high-resolution XPS spectra was also carried out, making it possible to estimate the bonding state of carbon and oxygen. The C 1s peaks of GO (Figure 3a), GO-100 (Figure 3b) and GO-110 (Figure 3c) can be assigned to three peaks being C-C (284.6 eV), C-O (286.6 eV) and $\mathrm{COOH}(289.0 \mathrm{eV})$, respectively [27-29]. For the sample GO-120 (Figure 3d), in addition to the three peaks mentioned above, one more peak appears at the binding energy of $285.2 \mathrm{eV}$, which can be attributed to $\mathrm{C}-\mathrm{OH}$ groups [30-32]. Figure 4 a shows the contents of different oxygen-containing surface functional groups on GO, GO-100, GO-110 and GO-120 calculated by fitting the C 1s peaks in Figure 3. There are two types of functional groups on the surface of GO/GO-100/GO-110, COOH and C-O. After $\mathrm{HNO}_{3}$ treatment, the content of $\mathrm{C}-\mathrm{O}$ group shows a slight increase. When the temperature of hydrothermal reaction further reaches $120^{\circ} \mathrm{C}$, both the $\mathrm{COOH}$ and $\mathrm{C}-\mathrm{O}$ group content decreased moderately, while the $\mathrm{C}-\mathrm{OH}$ group accounts for approximately $40 \%$. 
Table 1. Contents of $\mathrm{C}$ and $\mathrm{O}$ of different samples.

\begin{tabular}{cccc}
\hline Sample & C (wt.\%) & O (wt.\%) & C/O $^{\mathbf{1}}$ \\
\hline GO & 53.14 & 46.86 & 1.51 \\
GO-100 & 49.40 & 50.60 & 1.30 \\
GO-110 & 48.82 & 51.18 & 1.27 \\
GO-120 & 47.97 & 52.04 & 1.23 \\
\hline \multicolumn{4}{c}{ Atomic ratio. }
\end{tabular}
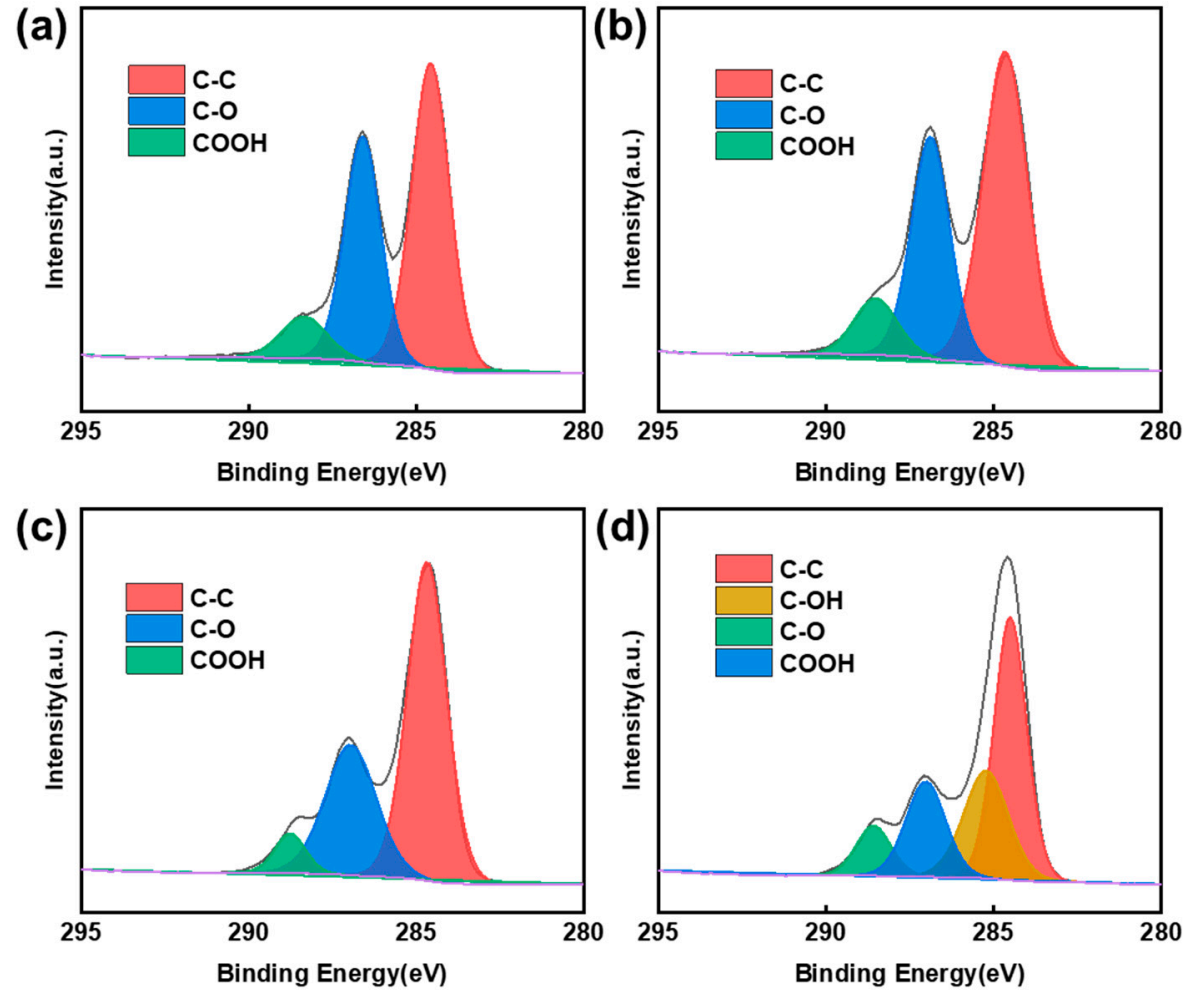

Figure 3. XPS C 1s analysis of (a) GO, (b) GO-100, (c) GO-110 and (d) GO-120.
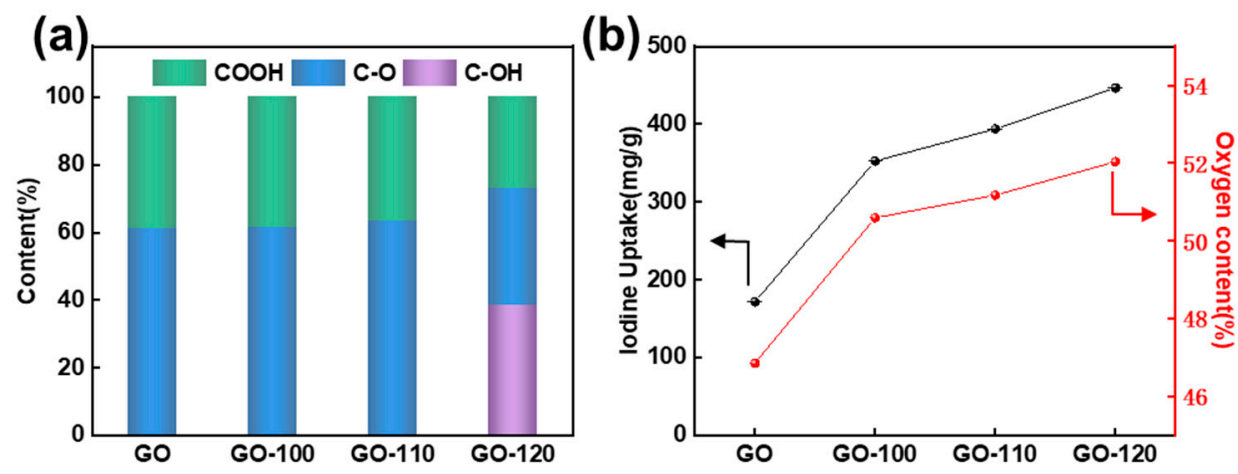

Figure 4. (a) contents of different oxygen-containing groups and (b) iodine uptake performance of GO, GO-100, GO-110 and GO-120.

\subsection{The Iodine Adsorption Performance}

Considering the high oxygen content and the diversity of surface functional groups, the obtained sample was used as a solid adsorbent for iodine vapor capture. The adsorption measurements were performed in a sealed vessel at $75^{\circ} \mathrm{C}$ under atmospheric pressure $[27,33]$. The adsorption amount was monitored by recording the sample mass as a function of time. Figure $4 \mathrm{~b}$ shows the iodine 
adsorption performance of the four samples. Although the saturated iodine adsorption capacity of the $\mathrm{HNO}_{3}$-treated GOs was not as high as that of the oxygen-rich activated carbon with ultra-high surface area used as adsorbent in our previous work $\left(6.44 \mathrm{~g} \cdot \mathrm{g}^{-1}\right)$ [25], the relationship between the capture value and the oxygen content is evident in Figure $4 \mathrm{~b}$. The iodine capture capacity increased from $0.17 \mathrm{~g} \cdot \mathrm{g}^{-1}$ to $0.44 \mathrm{~g} \cdot \mathrm{g}^{-1}$ proportionally with increasing oxygen content (Table 1 ). The GO-120 shows the highest saturation value. Figure 5 shows the EDS and XPS results of GO-120 after adsorption of iodine. The elemental mapping displayed in Figure $5 c$,d proves its oxygen-rich nature and confirms the successful adsorption of iodine on it. Figure 5 e shows the wide scanning XPS spectrum of GO-120 after iodine adsorption. It can be seen that in addition to the two peaks corresponding to $\mathrm{C} 1 \mathrm{~s}$ and $\mathrm{O}$ $1 \mathrm{~s}, \mathrm{I} 3 \mathrm{~d}$ peaks are also present in the spectrum, again illustrating the same point.

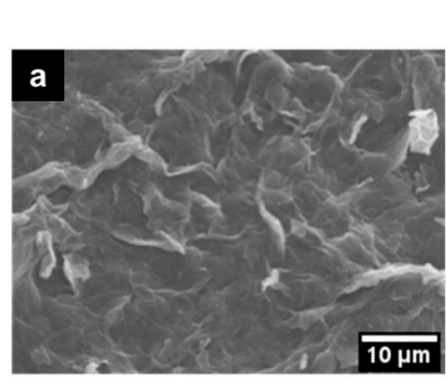

$\mathrm{OKa1}$
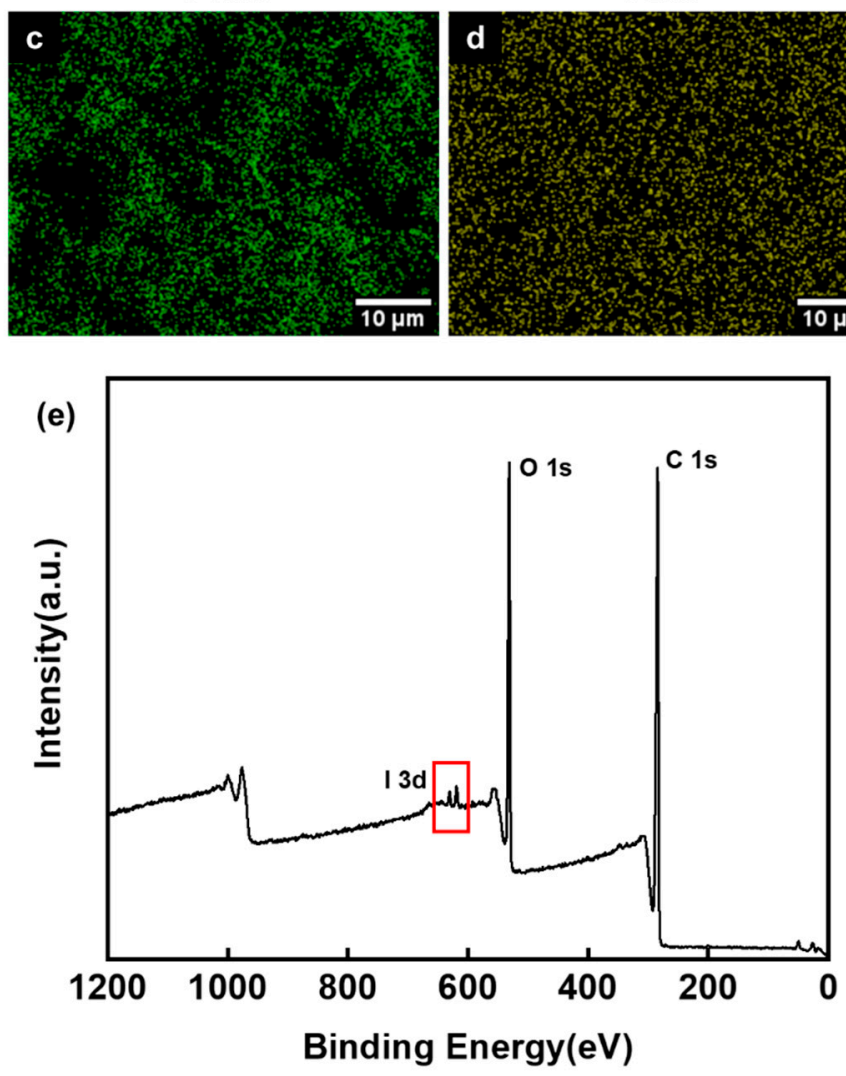

Figure 5. (a) SEM image, (b-d) elemental mapping images and (e) XPS wide scan spectrum of GO-120 after iodine adsorption.

\subsection{DFT Calculation}

Based on the above experimental results, the positive influence of high oxygen content deriving from the abundant oxygen-containing surface functional groups for the iodine adsorption performance can be confirmed. To further deeply reveal the effects of different oxygen functional groups, 
the interactions between the carboxyl group (-COOH), hydroxyl group $(-\mathrm{OH})$, epoxy group (-COC) and carbonyl group $(-\mathrm{C}=\mathrm{O})$ on the carbon surface and iodine molecules were studied via density functional theory calculations. In the calculations, two models (the perfect model and the defected model) were performed. Firstly, perfect graphene surfaces were considered. All the oxygen-containing functional groups were placed on the edged and central position over the graphene surface (Figure S1, Supplementary Materials). On the perfect graphene surface, $-\mathrm{COOH}$ group and $-\mathrm{C}=\mathrm{O}$ were only placed on edged position (perfect-edged- $\mathrm{COOH}$ and perfect-edged- $\mathrm{C}=\mathrm{O}$ ) and $-\mathrm{COC}$ group was only placed on central position (perfect-central-COC) due to the instability issue. Due to the impossibility of centrally located structure of $\mathrm{COOH}$, the addition of $-\mathrm{COOH}$ group around perfect-central-OH group and around perfect-central-COC was not considered [34].

Figure 6 shows the B3LYP functional-optimized structures for graphene- $\mathrm{I}_{2}\left(\mathrm{C}_{24} \mathrm{H}_{12}-\mathrm{I}_{2}\right)$, perfect-edged-COOH- $\mathrm{I}_{2}$, perfect-edged-OH-I $\mathrm{I}_{2}$, perfect-edged-C $=\mathrm{O}-\mathrm{I}_{2}$, perfect-central-OH- $\mathrm{I}_{2}$ and perfect-central-COC- $\mathrm{I}_{2}$ systems. The corresponding adsorption energies are summarized in Table $\mathrm{S} 1$ and plotted in Figure 7. Figure 6a shows the interaction between $\mathrm{I}_{2}$ and pure graphene (the $\mathrm{C}_{24} \mathrm{H}_{12}$ model) without any oxygen functional groups. As a result, the I-C distance is very long $(8.431 \AA)$, and the I-I bond distance is unchanged compared with the I-I distance in an isolated $\mathrm{I}_{2}$ molecule $(2.863 \AA)$. Accordingly, the adsorption energy is estimated to be $+0.3 \mathrm{~kJ} \cdot \mathrm{mol}^{-1}$ (unstable), suggesting a weak interaction between iodine molecule and graphene. In comparison, when iodine molecules are exposed to the oxygen-containing graphene surfaces, the I-I bond distances become longer in all cases (Figure $6 \mathrm{~b}-\mathrm{f}$ and Table S2), indicating the iodine molecules were attracted to the oxygen-containing groups. Interestingly, it's found that iodine molecules would bind not only with oxygen atoms but also with carbon atoms activated by nearby oxygen functional groups (within red circles). For example, three carbons atoms were calculated to coordinate with the iodine molecule with the bond distances of $3.202 \AA$ in perfect-edged-COOH- $\mathrm{I}_{2}$ system, $2.970 \AA$ in perfect-edged-OH- $\mathrm{I}_{2}$ system and $3.297 \AA$ in perfect-edged-C $=\mathrm{O}-\mathrm{I}_{2}$ system, which are much shorter than that of $\mathrm{I}-\mathrm{C}$ distance between $\mathrm{I}_{2}$ and pure graphene. It means that the introduction of the oxygen functional groups on the graphene surface would activate the nearby carbon atoms, enhancing the interaction between $I_{2}$ and graphene. Meanwhile, the bond distances between iodine molecules and two oxygen atoms in perfect-central-OH- $\mathrm{I}_{2}$ system and perfect-central-COC- $\mathrm{I}_{2}$ system were calculated to be $2.107 \AA$ and $2.720 \AA$, respectively. Accordingly, the binding energy of $I_{2}$ on surface oxygen functionalized graphene became negative approximately from -9.2 to $-81.4 \mathrm{~kJ} \cdot \mathrm{mol}^{-1}$ (Figure 7), indicating the enhanced adsorption of $I_{2}$ on the oxygen functionalized graphene compared to that on the graphene $\left(\mathrm{C}_{24} \mathrm{H}_{12}\right.$ model). Notably, the binding energy of $\mathrm{I}_{2}$ on perfect-central-OH reached a high of $-81.4 \mathrm{~kJ} \cdot \mathrm{mol}^{-1}$, which is much larger than other oxygen functional groups, showing the strongest interaction between $\mathrm{I}_{2}$ and $\mathrm{OH}$-terminated graphene. This calculation result is well consistent with the experimental results of the highest iodine capture for GO-120, where GO-120 also contains more -OH than the other samples.

The aforementioned perfect-edged and perfect-central structures are constructed based on perfect graphene structures. However, due to the strong oxidation of the concentrated $\mathrm{HNO}_{3}$, the structures of $\mathrm{HNO}_{3}$-treated GO (GO-100, GO-110 and GO-120) are more or less damaged. Therefore, other models with different degrees of defects on graphene were considered as well (Figure S2). Here, three typical types (single defect (D1), double defects (D2) and triple defects (D3) were constructed in their initial structures) in Figure 8. The initial structures for the above three typical defects were optimized with B3LYP functional. On the edge of central defect over defected graphene surface, edged - $\mathrm{COOH}$ (defected-edged-COOH), $-\mathrm{OH}$ (defected-edged-OH), $-\mathrm{C}=\mathrm{O}$ (defected-edged- $\mathrm{C}=\mathrm{O}$ ) group and $-\mathrm{COC}$ (defected-central-COC) group near the edge of the defect were constructed. However, it was found that the defected-edged- $\mathrm{C}=\mathrm{O}$ group tends to transfer into $-\mathrm{COC}$ group automatically, thereby the iodine interaction on this group was not considered $[29,35]$. 

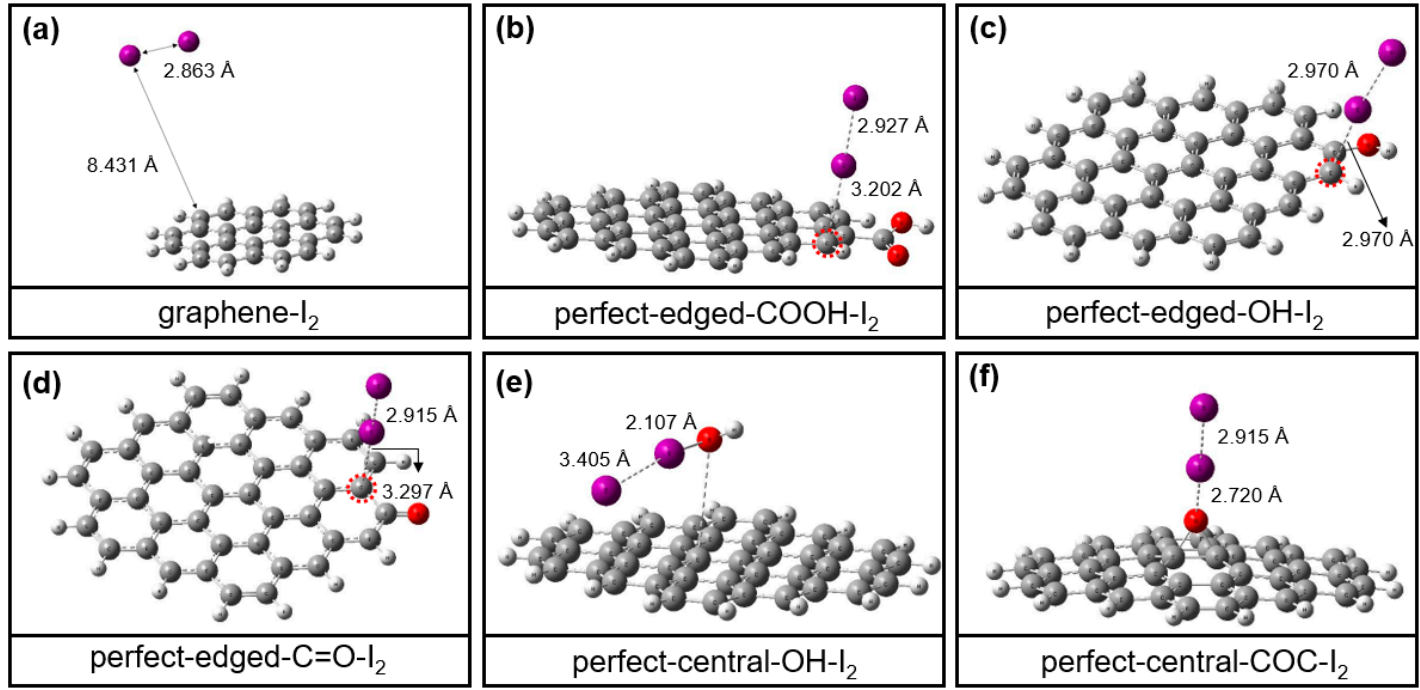

Figure 6. B3LYP functional-optimized structures for (a) graphene- $\mathrm{I}_{2}\left(\mathrm{C}_{24} \mathrm{H}_{12}-\mathrm{I}_{2}\right)$, (b) perfect-edged$\mathrm{COOH}-\mathrm{I}_{2}$ ， (c) perfect-edged-OH-I,$\quad$ (d) perfect-edged-C $=\mathrm{O}-\mathrm{I}_{2}$ ， (e) perfect-central-OH- $\mathrm{I}_{2}$ and (f) perfect-central-COC-I $\mathrm{I}_{2}$ systems.

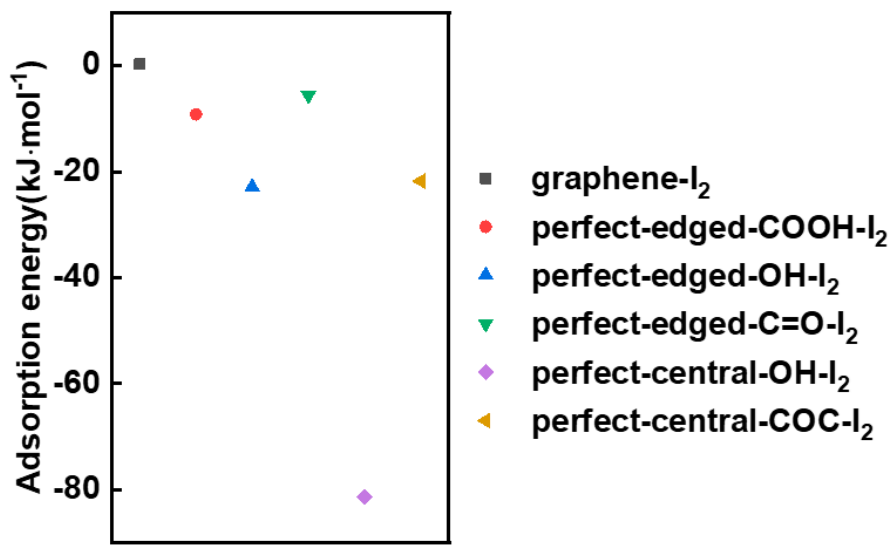

Figure 7. Adsorption energy of graphene- $\mathrm{I}_{2}\left(\mathrm{C}_{24} \mathrm{H}_{12}-\mathrm{I}_{2}\right)$, perfect-edged-COOH- $\mathrm{I}_{2}$, perfect-edged-OH- $\mathrm{I}_{2}$, perfect-edged-C $=\mathrm{O}-\mathrm{I}_{2}$, perfect-central-OH- $\mathrm{I}_{2}$ and perfect-central-COC- $\mathrm{I}_{2}$ systems.

The adsorption behavior of iodine by oxygen-containing groups on the graphene surface under different types of defect conditions was investigated next (Figure 9). Compared to the I-I bond lengths in iodine molecules alone (Figure 6a), it is evident that when iodine molecules interact with oxygen-containing groups on the surface of graphene of different defect types, the I-I bond lengths in iodine molecules are also increased to some extent, which is similar to what happens in the perfect model. This also indicates that the presence of oxygen-containing groups has a slight pull on the iodine molecule. Similarly, in the defected models, the oxygen functional groups on the graphene surface, such as the carboxyl groups in double defects and triple defects structures, can activate the nearby carbon and hydrogen atoms (in red circles) to form adsorption active sites. In addition to this, the average bond length between - $\mathrm{OH}$ and iodine molecules was found to be the shortest regardless of the defected structure. This is also in agreement with the experimental results in GO-120 sample. The adsorption energies of different oxygen-containing functional groups on the surface of different defected graphene for iodine molecules were further calculated. As shown in Figure 10, the adsorption energies of all the oxygen-containing defected graphene for iodine molecules are located in the range of $-5.3 \mathrm{~kJ} \cdot \mathrm{mol}^{-1}$ (double defects-COC) to $-42.2 \mathrm{~kJ} \cdot \mathrm{mol}^{-1}$ (single defect-OH). In general, the -OH group tend to have a larger adsorption energy averagely (Figure 11). This explains why GO-120 displays the highest iodine uptake capacity. Such results further indicate that the introduction of oxygen-containing 
functional groups on the surface of both the perfect and defective models allows the oxygen-containing functional groups to interact directly with the iodine molecules, as well as to activate the surrounding carbon atoms. Due to the synergistic promotion of these two interactions, the adsorption capacity of graphene to iodine molecules is increased.
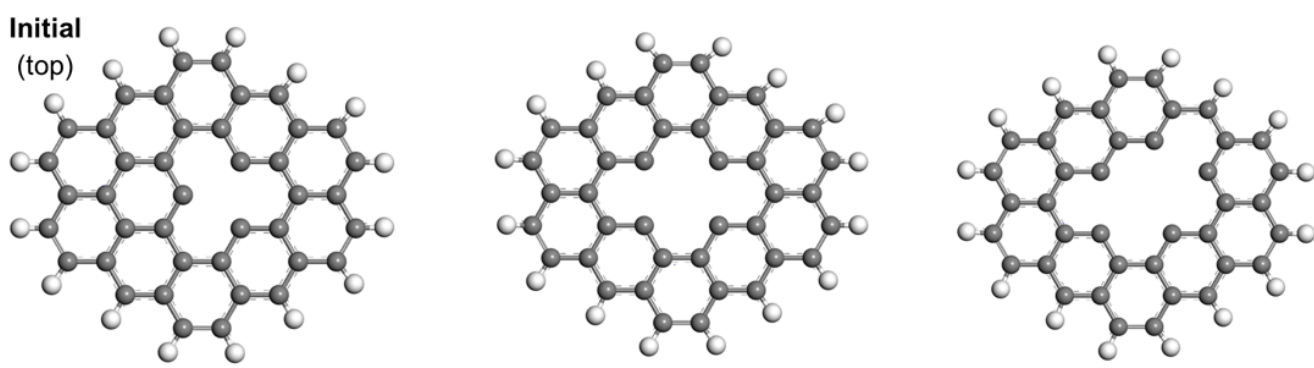

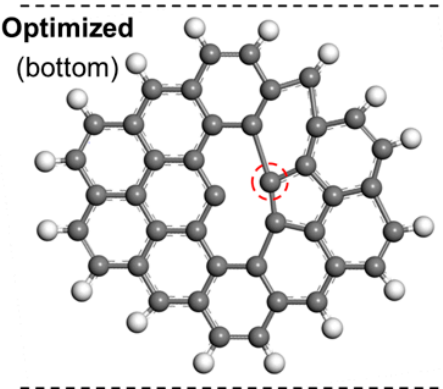

D1

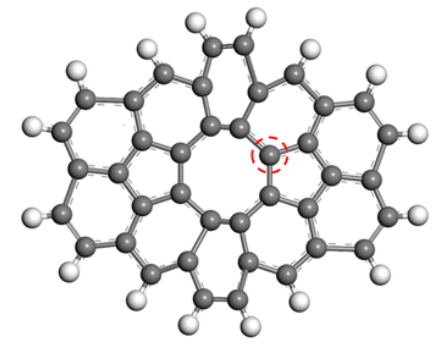

D2

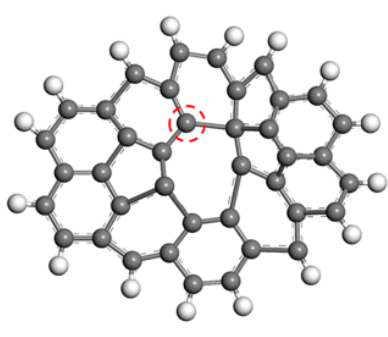

Figure 8. The structures for three typical defects (single defect (D1), double defects (D2) and triple defects (D3)) on graphene: The initial structures (top) and the optimized structures (bottom).

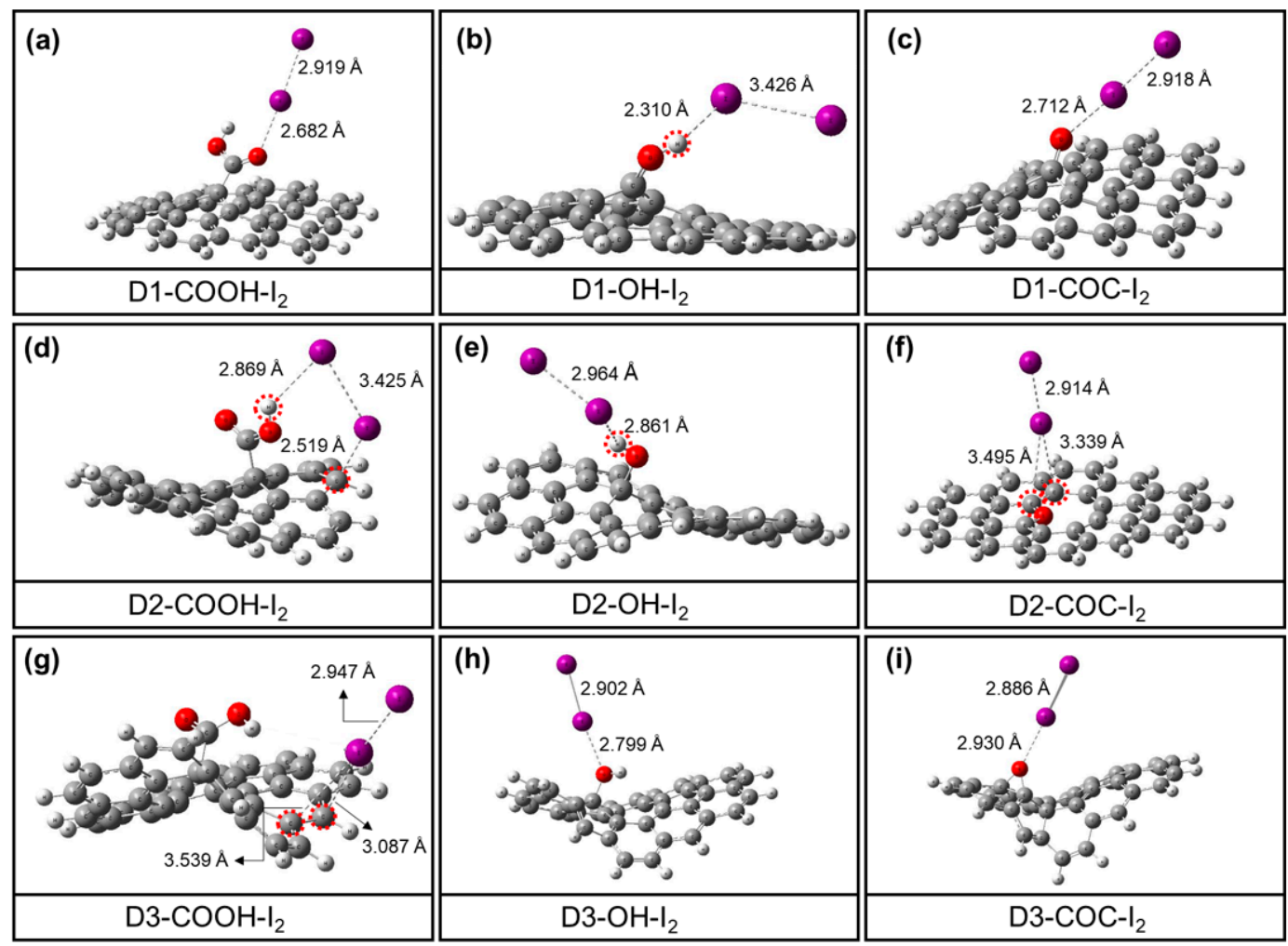

Figure 9. Optimized structures for single-defect structure $(\mathbf{a}-\mathbf{c})$, double-defects structure $(\mathbf{d}-\mathbf{f})$ and triple-defects structure (g-i) with B3LYP functional. 


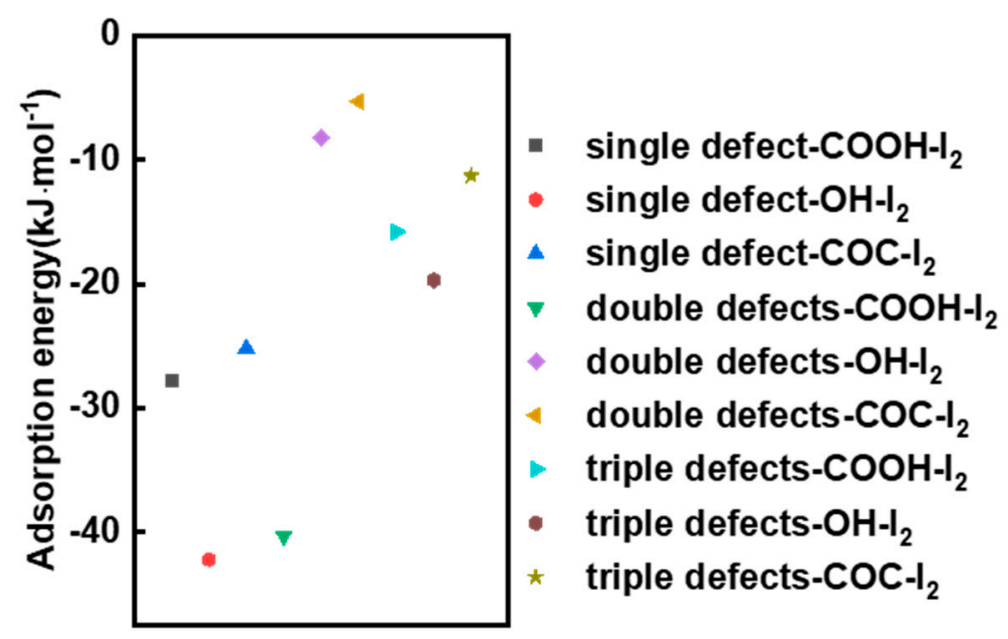

Figure 10. Adsorption energy of the iodine molecules and the oxygen functional groups in single-defect structure (D1), double-defects structure (D2) and triple-defects structure (D3).

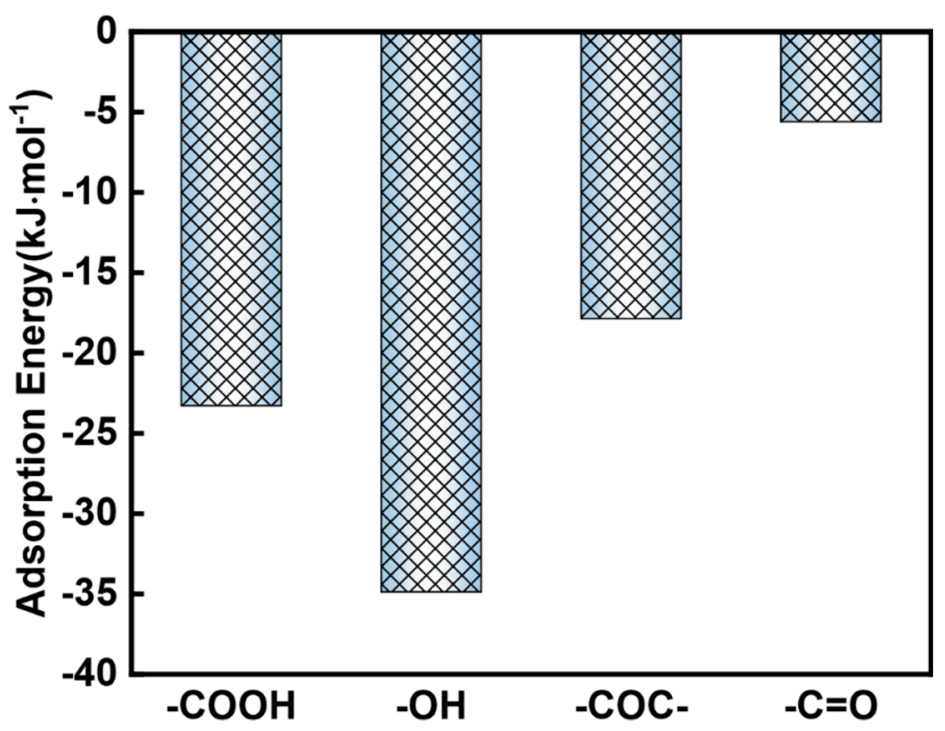

Figure 11. Average adsorption energy of different oxygen functional groups.

\section{Conclusions}

In conclusion, a series of graphene oxide nanosheets with rich surface oxygen functional groups were prepared as solid adsorbents for radioactive iodine adsorption after a simple nitric acid treatment. A positive correlation was observed between the iodine uptake capacity and the oxygen content and the diversities of oxygen functional groups according to the experimental results. The sample GO-120, which possesses an ultrahigh oxygen content of up to $52.04 \mathrm{wt} . \%$ and most abundant oxygen functional groups, displays the highest iodine uptake capacity. To further prove the effects of oxygen on iodine adsorption, the density functional theory calculation was also carried out. Both perfect and defected surfaces were considered on the surface of graphene to match the real experimental material. The DFT calculation results show that the presence of oxygen functional groups enhances the interaction between the iodine molecules and adsorbents. There is a covalent bond forming during the interaction between iodine molecule and $\mathrm{O}$ atoms or $\mathrm{C} / \mathrm{H}$ atoms activated by nearby oxygen functional groups. Among the four kinds of oxygen functional groups, $-\mathrm{OH}-\mathrm{I}_{2}$ system displays the highest adsorption energy averagely $\left(-34.88 \mathrm{~kJ} \cdot \mathrm{mol}^{-1}\right)$ while the adsorption energy of -COOH and -COC- groups is relatively lower $\left(-23.28 \mathrm{~kJ} \cdot \mathrm{mol}^{-1}\right.$ and $-17.87 \mathrm{~kJ} \cdot \mathrm{mol}^{-1}$, respectively). The $-\mathrm{C}=\mathrm{O}$ group has the least obvious influence for the average adsorption energy is only $-5.6 \mathrm{~kJ} \cdot \mathrm{mol}^{-1}$. The effects of 
different oxygen functional groups are systematically investigated in this work. which opens up a new research direction for the design of carbon materials used as iodine adsorbents in the future.

Supplementary Materials: The following are available online at http://www.mdpi.com/1996-1944/13/24/5770/s1, Table S1: Adsorption energy values of different oxygen-containing group, Table S2: Bond distances of different oxygen functional groups, Figure S1: Distinct structures of oxygen functional groups on perfect surface of graphene. The carbon atoms activated by neighboring oxygen functional groups are within red circles, Figure S2: Distinct structures of oxygen functional groups on three kinds of defected surfaces of graphene. The carbon atoms activated by neighboring oxygen functional groups are within red circles.

Author Contributions: Conceptualization, Q.Z.; Characterization and analysis, Q.Z. and Y.G.; DFT Calculation, H.K. and Q.Z.; writing-original draft preparation, Q.Z.; writing-review and editing, Y.G., J.W. and Z.X.; supervision, Z.X. and J.W.; project administration, S.W.; funding acquisition, Z.X. and S.W. All authors have read and agreed to the published version of the manuscript.

Funding: This research was funded by the National Natural Science Foundation of China (No. 21906128, No.11775166), the Young Talent Support Plan of Xi'an Jiaotong University (No. 7121181102), the program of Fundamental Research Funds for the Central Universities (No. XJH012019018) and the key project of Intergovernmental International Scientific and Technological Innovation Cooperation in China under Grant No.2016YFE0128900.

Conflicts of Interest: The authors declare no conflict of interest.

\section{References}

1. Yoshida, N.; Kanda, J. Tracking the Fukushima radionuclides. Science 2012, 336, 1115-1116. [CrossRef] [PubMed]

2. Vellingiri, K.; Kim, K.H.; Pournara, A.; Deep, A. Towards high-efficiency sorptive capture of radionuclides in solution and gas. Prog. Mater. Sci. 2018, 94, 1-67. [CrossRef]

3. Kintisch, E. Congress tells DOE to take fresh look at recycling spent reactor fuel. Science 2005, 310, 1406. [CrossRef] [PubMed]

4. Ewing, R.C.; Von Hippel, F.N. Nuclear waste management in the United States-Starting over. Science 2009, 325, 151-152. [CrossRef] [PubMed]

5. Soelberg, N.R.; Garn, T.G.; Greenhalgh, M.R.; Law, J.D.; Jubin, R.; Strachan, D.M.; Thallapally, P.K. Radioactive iodine and krypton control for nuclear fuel reprocessing facilities. Sci. Technol. Nucl. Install. 2013, 2013, 702496. [CrossRef]

6. Mushkacheva, G.; Rabinovich, E.; Privalov, V.; Povolotskaya, S.; Shorokhova, V.; Sokolova, S.; Turdakova, V.; Ryzhova, E.; Hall, P.; Schneider, A.B.; et al. Thyroid abnormalities associated with protracted childhood exposure to $131 \mathrm{I}$ from atmospheric emissions from the Mayak weapons facility in Russia. Radiat. Res. 2006, 166, 715-722. [CrossRef]

7. Subrahmanyam, K.S.; Sarma, D.; Malliakas, C.D.; Polychronopoulou, K.; Riley, B.J.; Pierce, D.A.; Chun, J.; Kanatzidis, M.G. Chalcogenide aerogels as sorbents for radioactive iodine. Chem. Mater. 2015, 27, 2619-2626. [CrossRef]

8. Liu, S.; Wang, N.; Zhang, Y.; Li, Y.; Han, Z.; Na, P. Efficient removal of radioactive iodide ions from water by three-dimensional $\mathrm{Ag} 2 \mathrm{O}-\mathrm{Ag} / \mathrm{TiO} 2$ composites under visible light irradiation. J. Hazard. Mater. 2014, 284, 171-181. [CrossRef]

9. Subrahmanyam, K.S.; Malliakas, C.D.; Sarma, D.; Armatas, G.S.; Wu, J.; Kanatzidis, M.G. Ion-Exchangeable Molybdenum Sulfide Porous Chalcogel: Gas Adsorption and Capture of Iodine and Mercury. J. Am. Chem. Soc. 2015, 137, 13943-13948. [CrossRef]

10. Xiao, K.; Liu, H.; Li, Y.; Yang, G.; Wang, Y.; Yao, H. Excellent performance of porous carbon from urea-assisted hydrochar of orange peel for toluene and iodine adsorption. Chem. Eng. J. 2020, 382, 122997. [CrossRef]

11. Chapman, K.W.; Chupas, P.J.; Nenoff, T.M. Radioactive iodine capture in silver-containing mordenites through nanoscale silver iodide formation. J. Am. Chem. Soc. 2010, 132, 8897-8899. [CrossRef]

12. Pham, T.C.T.; Docao, S.; Hwang, I.C.; Song, M.K.; Choi, D.Y.; Moon, D.; Oleynikov, P.; Yoon, K.B. Capture of iodine and organic iodides using silica zeolites and the semiconductor behaviour of iodine in a silica zeolite. Energy Environ. Sci. 2016, 9, 1050-1062. [CrossRef]

13. Pei, C.; Ben, T.; Xu, S.; Qiu, S. Ultrahigh iodine adsorption in porous organic frameworks. J. Mater. Chem. A 2014, 2, 7179-7187. [CrossRef] 
14. Wang, P.; Xu, Q.; Li, Z.; Jiang, W.; Jiang, Q.; Jiang, D. Exceptional Iodine Capture in 2D Covalent Organic Frameworks. Adv. Mater. 2018, 30, 1801991. [CrossRef]

15. Wang, C.; Wang, Y.; Ge, R.; Song, X.; Xing, X.; Jiang, Q.; Lu, H.; Hao, C.; Guo, X.; Gao, Y.; et al. A 3D Covalent Organic Framework with Exceptionally High Iodine Capture Capability. Chem. Eur. J. 2018, 24, 585-589. [CrossRef]

16. Li, B.; Dong, X.; Wang, H.; Ma, D.; Tan, K.; Jensen, S.; Deibert, B.J.; Butler, J.; Cure, J.; Shi, Z.; et al. Capture of organic iodides from nuclear waste by metal-organic framework-based molecular traps. Nat. Commun. 2017, 8, 485. [CrossRef]

17. Ren, Y.Y.; Zhang, W.; Zhu, Y.; Wang, D.G.; Yu, G.; Kuang, G.C. Nitrogen-rich porous polyaminal network as a platform for iodine adsorption through physical and chemical interaction. J. Appl. Polym. Sci. 2018, 135, 6-11. [CrossRef]

18. Hijazi, A.; Azambre, B.; Finqueneisel, G.; Vibert, F.; Blin, J.L. High iodine adsorption by polyethyleneimine impregnated nanosilica sorbents. Microporous Mesoporous Mater. 2019, 288, 109586. [CrossRef]

19. Yao, C.; Li, G.; Wang, J.; Xu, Y.; Chang, L. Template-free synthesis of porous carbon from triazine based polymers and their use in iodine adsorption and $\mathrm{CO}_{2}$ capture. Sci. Rep. 2018, 8, 1867. [CrossRef]

20. Guo, B.; Li, F.; Wang, C.; Zhang, L.; Sun, D. A rare (3,12)-connected zirconium metal-organic framework with efficient iodine adsorption capacity and $\mathrm{pH}$ sensing. J. Mater. Chem. A 2019, 7, 13173-13179. [CrossRef]

21. Deng, L.Y.; Xu, G.R.; Li, G.B. Surface properties and adsorption characteristics to methylene blue and iodine of adsorbents from sludge. Water Sci. Technol. 2010, 62, 1705-1712. [CrossRef]

22. Zyryanov, S.S.; Kruzhalov, A.V.; Neshov, F.G.; Ryabukhin, O.V.; Kuznetsov, M.V. Investigation of a stainless-steel surface irradiated with protons in an iodine medium. J. Surf. Investig. 2013, 7, 322-327. [CrossRef]

23. Li, K.; Zhao, Y.L.; Deng, J.; He, C.H.; Ding, S.J.; Shi, W.Q. Adsorption of radioiodine on $\mathrm{Cu}_{2} \mathrm{O}$ surfaces: A first-principles density functional study. Acta Phys. Chim. Sin. 2016, 32, 2264-2270. [CrossRef]

24. Banerjee, D.; Chen, X.; Lobanov, S.S.; Plonka, A.M.; Chan, X.; Daly, J.A.; Kim, T.; Thallapally, P.K.; Parise, J.B. Iodine Adsorption in Metal Organic Frameworks in the Presence of Humidity. ACS Appl. Mater. Interfaces 2018, 10, 10622-10626. [CrossRef]

25. Xu, Z.; Zhang, Q.; Gao, Y.; Wang, S.; Lv, Y.; Kobayashi, H.; Wang, J. Exceptional iodine uptake in intrinsic oxygen-rich microporous carbons. (unpublished work).

26. Rustam, L.; Jeremias, F.; Henninger, S.K.; Wolff, T.; Munz, G.M. Tuning of adsorbent properties-Oxidative hydrophilization of activated carbon monoliths for heat storage applications. Energy Build. 2019, 196, $206-213$. [CrossRef]

27. Zhang, Q.M.; Zhai, T.L.; Wang, Z.; Cheng, G.; Ma, H.; Zhang, Q.P.; Zhao, Y.H.; Tan, B.; Zhang, C. Hyperporous Carbon from Triptycene-Based Hypercrosslinked Polymer for Iodine Capture. Adv. Mater. Interfaces 2019, 6, 1900249. [CrossRef]

28. Wang, X.; Kholmanov, I.; Chou, H.; Ruoff, R.S. Simultaneous Electrochemical Reduction and Delamination of Graphene Oxide Films. ACS Nano 2015, 9, 8737-8743. [CrossRef]

29. Dreyer, D.R.; Park, S.; Bielawski, C.W.; Ruoff, R.S. The chemistry of graphene oxide. Chem. Soc. Rev. 2010, 39, 228-240. [CrossRef]

30. Huang, Z.; Li, Z.; Zheng, L.; Zhou, L.; Chai, Z.; Wang, X.; Shi, W. Interaction mechanism of uranium (VI) with three-dimensional graphene oxide-chitosan composite: Insights from batch experiments, IR, XPS, and EXAFS spectroscopy. Chem. Eng. J. 2017, 328, 1066-1074. [CrossRef]

31. Yang, M.; Jiang, T.J.; Wang, Y.; Liu, J.H.; Li, L.N.; Chen, X.; Huang, X.J. Enhanced electrochemical sensing arsenic(III) with excellent anti-interference using amino-functionalized graphene oxide decorated gold microelectrode: XPS and XANES evidence. Sens. Actuators B Chem. 2017, 245, 230-237. [CrossRef]

32. Pathak, A.K.; Borah, M.; Gupta, A.; Yokozeki, T.; Dhakate, S.R. Improved mechanical properties of carbon fiber/graphene oxide-epoxy hybrid composites. Compos. Sci. Technol. 2016, 135, 28-38. [CrossRef]

33. An, S.; Zhu, X.; He, Y.; Yang, L.; Wang, H.; Jin, S.; Hu, J.; Liu, H. Porosity Modulation in Two-Dimensional Covalent Organic Frameworks Leads to Enhanced Iodine Adsorption Performance. Ind. Eng. Chem. Res. 2019, 58, 10495-10502. [CrossRef]

34. Yang, F.; Ma, X.; Cai, W.B.; Song, P.; Xu, W. Nature of Oxygen-Containing Groups on Carbon for High-Efficiency Electrocatalytic $\mathrm{CO}_{2}$ Reduction Reaction. J. Am. Chem. Soc. 2019, 141, 20451-20459. [CrossRef] 
35. Thomas, H.R.; Day, S.P.; Woodruff, W.E.; Vallés, C.; Young, R.J.; Kinloch, I.A.; Morley, G.W.; Hanna, J.V.; Wilson, N.R.; Rourke, J.P. Deoxygenation of graphene oxide: Reduction or cleaning? Chem. Mater. 2013, 25, 3580-3588. [CrossRef]

Publisher's Note: MDPI stays neutral with regard to jurisdictional claims in published maps and institutional affiliations.

(C) 2020 by the authors. Licensee MDPI, Basel, Switzerland. This article is an open access article distributed under the terms and conditions of the Creative Commons Attribution (CC BY) license (http://creativecommons.org/licenses/by/4.0/). 